\title{
Aspirations Are Not Enough: Barriers to Educational Attainment for Youth Involved with Child Welfare
}

\author{
Christina Dimakos \\ University of Toronto, Canada
}

Colleen Loomis, Blaise O’Malley, Sylvie Lamont \& Gurmakh Singh

Wilfrid Laurier University and Balsillie School of International Affairs, Canada

Janette Pelletier

University of Toronto, Canada

Brian Christens

Vanderbilt University, USA

Carrie Wright

Applied Research Innovation and Evaluation Services, Canada

Ray DeV Peters

Queens University, Canada

\begin{abstract}
Children of families involved with child welfare services are considered high-risk and are vulnerable to developing problems in a number of domains. In particular, educational achievement among this population tends to be lower relative to general population peers. The goal of this qualitative study was to understand the educational aspirations and subsequent pathways of young adults with former child welfare involvement. Semi-structured interviews were conducted with seven young adults (mean age of 31 years) from Ontario, Canada about their educational aspirations in high school and factors that served as facilitators and obstacles to their achievement. The results indicate youth had high hopes and dreams for their future in high school. However, complex challenges impeded the realization of these dreams. Although all seven participants initiated post-secondary programs, only one reached successful completion. None of the young adults achieved the educational and occupational dreams they had in high school. Nevertheless, returning to school remains a prominent future goal for most participants. Despite significant challenges and unrealized educational aspirations, youth with child welfare experiences continue to place high value on education in ins piring hope and optimism for the future. Addressing barriers to educational achievement for youth with child welfare involvement remains an important focus to help educational aspirations become a reality.
\end{abstract}

Keywords: Children's Aid Society; Educational Achievement; Educational Aspirations; High-Risk Youth.

\section{Introduction}

Nearly worldwide, the attainment of post-secondary education is regarded as a marker of success, and efforts to help young people realize their educational aspirations abound. However, children of families involved with child welfare services are considered a vulnerable population and educational achievement among this group tends to lag behind that of their peers. Given the overall higher return on human investment developed through higher education (Finnie, 2012), it seems more important than ever to understand the educational aspirations and eventual pathways of youth 
with past child welfare involvement. Uncovering the barriers and facilitators involved in the educational participation of these high-risk youth seems especially important in deepening our knowledge of these aspects and guiding educators and policymakers towards developing more effective interventions (Flynn \& Tessier, 2011). The current study aimed to address this need by interviewing a group of young adults with previous child welfare involvement about the long-term outcomes of their educational aspirations and eventual pathways taken ten years after leaving high school.

For some youth, the experience of abuse, neglect, conflict, or family breakdown contribute to the separation from their family of origin and placement in alternative living settings (Heerde et al., 2018). The Canadian Child Welfare Research Portal (2021) defines "out-of-home care" as voluntary care agreements and placements in residential, foster, community, or kinship care. Children are placed in out-of-home care when child welfare authorities deem it is unsafe for them to remain in the family home. Decisions regarding when, and under what circumstances, a child should be removed from the parental home and placed in care is complex and fraught with emotional and intellectual challenges (O'Sullivan, 2011). Although great emphasis is placed on keeping children at home and supporting families to stay together, out-of-home placements are often necessary to ensure a child's wellbeing (Ontario Association of Children's Aid Societies [OACAS], 2021).

Significant differences exist between nations in terms of legal and policy frameworks that determine the care population, types of care placements, and even the purpose of care itself (see Stein, 2019 for an international overview). In Canada, child welfare is locally governed and organizations are mandated by the Child and Family Services Act (1990) to promote the best interests, protection, and wellbeing of children. Data indicate that in 2019, there were an estimated 54,139 children in out-of-home care across Canada with 12,385 of those residing in the province of Ontario (Saint-Girons et al., 2020). Despite jurisdictional differences, ample research from a number of different countries has made clear that youth in out-of-home care face a multitude of challenges. Their families of origin often struggle with dysfunction and instability, mental illness, substance abuse, neglect, poverty and inadequate housing, unemployment, socioeconomic disadvantage, criminal justice system involvement, and high-risk parental lifestyles (Connor et al., 2004; Doyle, 2007; Esposito et al., 2013; James et al., 2006; Lindsey \& Shlonksy, 2008). In addition, families often lack access to social and community supports and services (Frensch \& Cameron, 2002), further complicating their ability to adequately care for their children (OACAS, 2021). Notably, children with child welfare involvement often have experiences of maltreatment and studies have linked early maltreatment to a host of severe short- and long-term negative outcomes on children's cognitive, behavioural, and socioemotional development (Hildyard \& Wolfe, 2002). It is not surprising, then, that relative to general population youth, this group frequently presents with higher levels of psychiatric and personality disorders (Burns et al., 2004), depression and substance use (Heerde et al., 2018), homelessness (Klodnick \& Samuels, 2020), adult imprisonment (Ryan et al., 2001), and school dropout (Courtney \& Terao, 2006). 
In some jurisdictions, case workers called to perform a home visit may decide against apprehending a child while in other cases removal is court sanctioned. In Ontario, the most common reasons for families becoming involved with the CAS include child exposure to partner violence, caregiver(s) with a problem, physical force or maltreatment, and inadequate supervision (OACAS, 2021). The vast majority (97\%) of investigations conducted by CAS result in the child remaining in the home while receiving supportive services (OACAS, 2021). In the United Kingdom (UK), children of families who are investigated overwhelmingly present with severe social, emotional, and behaviour disturbances, and often have experiences of physical, emotional, or sexual abuse, neglect and maltreatment, violence in the home, and severe parental rejection (Biehal, 2005). Kolko and colleagues (2010) found greater risk of heightened posttraumatic stress symptoms among a nationally representative sample of children and adolescents in the United States for whom a child welfare investigation occurred. As such, children from families with child welfare involvement can be considered a high-risk group. Indeed, Biehal and colleagues (2000) studied UK families with adolescents at risk of placement and found that improved child and family functioning was less likely to occur in families that were experiencing severe and chronic difficulties. In recognition of the elevated risk among this population, placement prevention programs now exist aimed at preventing the placement of children by addressing issues such as improving family cohesion, reducing peer aggression, and addressing recidivism and incarceration. In a comparison of outcomes study of young people at risk of placement in the U.K., Biehal (2005) found that families who received intensive, short-term prevention services were significantly less likely to enter placement. The author notes that it remains unclear as to whether placement prevention should be the marker of success, or if individual outcomes such as child wellbeing or child and family functioning may be more appropriate indicators.

\section{Out-of-Home Care and Education}

Historically, service providers have prioritized the medical, social, emotional, and mental health needs of children and youth in out-of-home care (Trout et al., 2008). More recently, however, attention has turned to the educational experiences and achievements of this population (Courtney et al., 2004). Data from the Ontario Looking after Children (OnLAC) project, a strengths-based approach to assessing children's development and promoting good parenting, found that between 2007 and 2010, only 24\% of 12-15-year-olds were reported by their caregivers as doing 'well' or 'very well' academically, significantly below the $72 \%$ reported by Canadian parents in the National Longitudinal Survey for Children and Youth (NLSCY; Stoddart, 2012). High school graduation rates are also below the norm in this population with only $42 \%$ graduating high school compared to the provincial rate of $75 \%$ (OACAS, 2008). Research conducted in other countries has found similar outcomes of lower overall academic achievement, lower high school graduation rates, and fewer entries to post-secondary education among youth from out-of-home care relative to their peers (Courtney et al., 2001).

Trout and colleagues (2008) conducted a literature review of 29 studies on the school and academic functioning of youth in out-of-home care. They found that overall, children in out-of-home care demonstrate a number of academic risks relative to nationally representative samples of school-aged children including lower average on measures of IQ, below grade-level performance, three times more likely to receive special education services, and more likely to be 
identified by teachers as at-risk. Additional school functioning risks were identified including higher grade retention and suspension rates, higher school dropout rates, and frequent changes in school settings (up to 10 placements in elementary school alone). Other research has found that frequent changes in placements often experienced by out-ofhome youth can result in more school changes and disruptions, and contribute to more academic upheavals (Rosenfeld \& Richman, 2003). Reid and Dudding (2006) summarize the main factors contributing to poor educational outcomes as starting school without the necessary tools for success, disengagement from home and school, frequent school moves, low expectations (by students and teachers reviewed below), poor school attendance, and inconsistent social supports. Inconsistent social supports and low academic expectations, in particular, have been identified by other scholars as contributing factors to poor academic achievement in this population (e.g., Courtney et al., 2001; Jackson \& McParlin, 2006; Stone, 2007).

More recently, Leonard and Gudiño (2021) explored school adaptation and its role in bolstering resilience among youth with child welfare involvement. The authors found that although a nuanced relationship, connection to school impacts known associations between adversity and youth outcomes such as severity and type of maltreatment. School adaptation profiles, i.e., the extent to which youth adapted to school, including feelings about school, interest in classes, academic performance, and relationships with teachers and peers, was related to future mental health with more severe maltreatment and poorer behavioural functioning at school predicting worse mental health outcomes. These findings strongly suggest that children and youth in out-of-home care face significant academic challenges and are likely to require more intense academic support to address these risks.

\section{Teachers and Post-Secondary Education}

The impact of teachers on the lives of students is undisputed. This impact may be positive or negative. Teachers have long been important role models for students (Bell \& Romano, 2015; Merdinger et al., 2005) and have intervened to reduce the negative influence of victimization for youth who feel unsafe at school (Coyle et al., 2021). Teachers' interests often align with their students and foster their educational and career development. Recent research in Indonesia compared aspirations teachers have for their primary students to those that students have for themselves (Relmasira et al., 2021). The study found that both teachers and students shared a vision of the need to develop creative ability but differed on which career that ability would be applied. Overall, there is clear evidence that teachers play an important role in educational processes, aspirations, and outcomes.

Teachers may also have a limiting or negative impact on students. A meta-analysis of 34 studies found that teachers hold negative implicit attitudes towards marginalized students (Pit-Ten \& Glock, 2019) and attitudes about a social group are expressed daily in exchanges with students. A recent study in Switzerland found teachers' classroom discourse influences the choices of students who have been tracked into vocational education (Delay, 2020). This issue is not solely confined to practising teachers. Negative attitudes towards students from lower socioeconomic status have been observed at the onset of initial teacher education (Glock \& Kleen, 2020; Robson et al., 2021). Given 
the literature reviewed, we might expect to find that the role of teachers in impacting students whose families are involved with child welfare services to have either a positive and negative influence on educational aspirations.

The role of teachers in fostering post-secondary educational aspirations may be viewed as additional work compounding an already full workload, and further, as a role that should be occupied by families or society more broadly. In many countries, teachers are overworked and underpaid (Organisation for Economic Cooperation and Development [OECD], 2021) and studies show that increases in salary are related to higher educational outcomes (e.g., in Russia; Lazareva \& Zakharov, 2020). In Canada, teacher compensation may play less of a role in fostering educational aspirations because the salaries and amount of work are superior to most other developed countries. $\ln$ 2015, a comparison of 2013 teachers' wages using the Purchasing Power Parity Index by the OECD found that Canada's teachers are the fifth highest paid among the 35 countries. Concerning the ratio of pay to hours worked, Canada also ranked as the fifth most favourable teacher compensation among OECD countries. As of 2020, the average actual salaries of lower secondary teachers in Canada remains above the average of EU22 and OECD (OECD, 2021). Whether teacher compensation correlates to teachers fostering students' post-secondary educational aspirations is an empirical question but beyond the scope of the present study.

The attainment of post-secondary education is widely regarded as a marker of success. In Canada, attendance in postsecondary education has increased in recent decades and higher education is quickly becoming the norm for many Canadian youth, in part due to its prerequisite for entry into many career paths (Fisher et al., 2009). Many youth with experiences of out-of-home care, however, are not of the same educational levels as that of their peers and often do not complete secondary or post-secondary education (Dill, 2012). A 2007 survey by the Ontario Association of Children's Aid Societies (2008) on the educational participation and success of children and youth in care reviewed 4,534 case files of current and former Crown wards, ages 16 to 21 . The survey found a post-secondary enrolment or completion rate of only $21 \%$, roughly half of the $40 \%$ rate found among general population youth. Watt and colleagues (2019) followed 3855 youth in Texas formerly in care from age 18 to 24 and found that only $1.5 \%$ received a bachelor's degree and $2 \%$ received an associate's degree or certificate, despite the state's tuition and fee waiver for foster youth. The generally poor educational outcomes among this population are likely caused by a number of factors including histories of maltreatment, complex trauma, inconsistent social supports, low educational expectations, and lack of access to educational assistance or advisement (Courtney et al., 2001), all of which can result in a number of deficits and impair youth's educational attainment (Cook et al., 2005).

Interestingly, these outcomes persist despite some studies showing high desire and motivation among these youth to excel academically. For example, using data from the Foster Youth Transitions to Adulthood Study, Courtney and colleagues (2001) found that out of the 113 youth who were interviewed, the vast majority desired not only to graduate from high school but also to enter (79\%) and complete (63\%) college. Flynn and Tessier (2011) studied the educational aspirations of 406 youth aged 18-20 enrolled in extended care and maintenance (ECM) in Ontario, a government transitional living program to support former youth in care. They found that virtually all ECM youth aspired to at least 
a high school diploma and that $52.2 \%$ of men and $79.5 \%$ of women hoped to attain a college, apprenticeship, or university qualification. Stoddart (2012) compared educational aspirations and expectations of youth residing in care and their primary caregivers in one Ontario child welfare organization to those documented by the National Longitudinal Survey of Children and Youth (NLSCY). The study found that youth's aspirations for their futures are generally higher than those of their caregivers with more youth hoping to achieve high school, trade, technical or vocational programs, and college than their caregivers. When compared to general population data, however, youth in care report slightly lower educational aspirations with $42 \%$ hoping to attend college and $33 \%$ hoping to attend university, compared to $52 \%$ and $27 \%$, respectively, reported by youth from the NLSCY. Among parents surveyed in the NLSCY, 75\% hoped their children would attend university compared to only $35 \%$ of the caregivers of youth in care. When combining college and university aspirations, the rate jumps to $87 \%$ for parents on the NLSCY versus $68 \%$ of the caregivers of youth in care. Caregivers of youth in care also place less importance on getting good grades. Among NLSCY parents, 76\% reported it was very important their children get good grades compared to 59\% of caregivers who reported the same for children in care. Although a direct causal link cannot be inferred, it may be reasonable to assume that caregivers and teachers who set high academic expectations for youth send the message that adults believe in them and this may be an important influence on educational outcomes (OACAS, 2008).

\section{Facilitative Conditions for Overcoming Adversity}

In an article summarizing the factors associated with the resilience of young people leaving care (and youth from disadvantaged family backgrounds, more generally), Stein (2008) shows that differences in outcomes and pathways are associated with the quality of care youth experience, transitions out of care, and supports received after leaving care. Resilience has been defined as the quality that enables some young people to find fulfilment in their lives despite disadvantaged backgrounds, adversity, or other pressures they may have experienced (Stein, 2008). Research has shown that the presence of a committed mentor or person outside the family better equips young people to overcome adversity primarily because providing a redeeming relationship can compensate for an insecure attachment with family figures, a state that may necessitate intervention in the first place (Newman, 2004). Indeed, spending time with youth, building relationships, and understanding their hopes and dreams is a critical factor shown to have important impacts on positive outcomes (Stoddart, 2012). In a recent qualitative study, Harder and colleagues (2021) investigated the role of mentoring in residential youth care and found that conversations between professionals and youth often aim at building a good relationship, coaching, determining treatment goals, and gaining insight into youth. In a study of the school experiences of 16 former foster youth, Clemens and colleagues (2017) found that youth internalized both implicit and explicit messages about education from family members, peers, professionals, and social programs, including teachers. These messages reflected a belief structure about who youth were as students and what they might be able to achieve. Messages were perceived as either supportive or discouraging, and youth in the study spoke about the substantial impact messaging had on their sense of self-worth and educational aspirations. Indeed, therapeutic models and approaches used in youth residential settings often aim to nurture a culture of resilience and wellbeing through positive and secure relationships (e.g., Holden et al., 2010). 


\section{The Current Study}

Given the overall higher return on human investment developed through higher education (Finnie, 2012), it seems more important than ever to understand the educational aspirations and pathways of youth with past child welfare involvement. Based on the circumstances that often bring these children to the attention of authorities, it can reasonably be assumed that they constitute a high-risk group in need of attention. Previous research has indicated the importance of understanding barriers and facilitators involved in the educational aspirations, attainment, and participation of high-risk youth to deepen our knowledge of these aspects and help develop more effective interventions (Flynn \& Tessier, 2011). This area of inquiry seems particularly relevant given the generally high hopes and dreams research has documented among this group. The objectives of this exploratory study are to: (1) Discover the long-term outcomes of educational aspirations and eventual pathways taken ten years after high school; (2) Identify factors that facilitate and impede the successful transition to, and completion of, post-secondary education.

\section{Methods}

\section{Participants}

The current sample $(\mathrm{n}=7$, Mage $=31.8$ years) was part of a larger longitudinal study about growing up in Ontario, Canada ( $\mathrm{N}=47$; see Table 1 for current participant demographics). Participants who had previously consented to be contacted for future research were phoned or emailed and invited to take part in a study about educational aspirations. Of those who responded and completed an interview, seven had previously self-identified as having prior involvement with the Children's Aid Society (CAS), a provincial child welfare organization. Although we did not intentionally recruit for this population, we saw an organic opportunity to better understand the lived educational experiences of this particular subset of participants. Two of the seven indicated they had been removed from the family home as children, though age and length of time of removal is unknown. Participants were remunerated $\$ 25$ for taking part in this study.

\section{Data Collection}

This study received approval from an institutional ethics review board and informed consent was appropriately obtained. Recruitment took place via email and phone. Interested participants took part in one-on-one, semi-structured interviews approximately 45-60 minutes in length using the video conferencing platform Zoom. Interviews were conducted in English. Using open-ended questions, participants were asked to reflect on their educational and occupational aspirations in high school, the people who influenced their aspirations, facilitators and obstacles to dream attainment, and their subsequent pathways. None of the interview questions directly asked about involvement with CAS and the interviewers were unaware of this factor. Interviews were recorded and stored on a secure database for researcher access. Interview audio files were uploaded to an automated transcription service (Sonix and Otter). Video files were deleted. 


\section{Data Analysis}

Interviews were analyzed using thematic content analysis. Using an inductive, iterative approach, data were approached without a priori hypotheses or preconceptions; rather, commonalities across participants' accounts emerged organically from the interviews. Initially, the lead researcher read through the interviews in their entirety to get a "sense" of what was happening in the data. Closer subsequent readings allowed for themes to emerge and important insights to be gleaned. Relevant words, phrases or sections were annotated using labels; these were then consolidated into larger overarching themes. Common themes were grouped together into increasingly abstracted categories. Once these categories were developed, they were shared with the remainder of the research team who reviewed and discussed the findings to ensure convergence and trustworthiness of the data. Analysis by demographic characteristics was not possible due to the relatively small sample size.

\section{Table 1}

Sociodemographic Characteristics of Participants $(N=7)$

Sociodemographic variable

\begin{tabular}{|c|c|}
\hline Age (years) $M(S D)$ & $31.8(0.41)$ \\
\hline \multicolumn{2}{|l|}{ Gender $n(\%)$} \\
\hline Male & $2(28.6)$ \\
\hline \multicolumn{2}{|l|}{ Ethnicity $n(\%)$} \\
\hline Indigenous & $1(14.3)$ \\
\hline Other & $1(14.3)$ \\
\hline \multicolumn{2}{|l|}{ Education $n(\%)$} \\
\hline Up to grade 12 & 3 \\
\hline \multicolumn{2}{|l|}{ Living situation $n(\%)$} \\
\hline At home with parents & 2 \\
\hline With friends & 1 \\
\hline Alone & 1 \\
\hline With partner & 3 \\
\hline \multicolumn{2}{|l|}{ Ever been homeless $n(\%)$} \\
\hline Yes & 3 \\
\hline No & 4 \\
\hline
\end{tabular}

Because the focus of the current study was on young adults with prior child welfare involvement, the sample size was determined a priori based on those participants who self-identified as falling into this high-risk group. Although 
predetermining sample size goes against conventions of qualitative research (Dworkin, 2012), we were limited to collecting data from those self-identified participants. For this reason, we were unable to sample to saturation.

\section{Results}

Overall, participants reported having high hopes and dreams in high school but faced a number of personal and structural barriers that prevented them from realizing those dreams. Of the 7 participants, only 4 (57\%) completed high school. However, nearly all $(6 ; 86 \%)$ started either a college $(5 ; 71 \%)$ or university $(2 ; 29 \%)$ program, though only one (14\%) completed it. All participants reported multiple job or career changes since leaving high school, ranging from two to four. None achieved the hopes and dreams they had in high school. In terms of eventual pathways, one participant was a receptionist, one was a social worker, and three were working in customer service; 2 (29\%) reported being unemployed at the time of the interview with one receiving social assistance. The most common future goal reported by 4 (57\%) participants was returning to school. The following section describes these themes in more detail. See Figure 1 for a schematic of our findings.

\section{High Hopes and Dreams in High School}

During high school, 5 participants (71\%) reported having high hopes for the future and intended to pursue fields such as law, nursing, medicine, sound engineering, and acting. All seven expressed occupational aspirations, i.e., career/job, whereas only one participant explicitly stated educational aspirations, though education may have been implied in all cases. For $5(71 \%)$, aspirations were motivated by money, financial security, or the opportunity for a better life. One participant said, "If I wanted to buy a house or earn more or things, a basic education of just like high school wasn't enough and that I would definitely need to pursue something further and have more of a career." Another participant described education as "the ticket" to a better life. Growing up in a low-income, single-parent household prompted this participant to say, "For me, it was like, I need to get an education. I need to move on. I need to somehow be able to be in a better position... I guess like that notion that if I wanted more and if I want to better, I needed to, you know, get an education." Another participant grew up in public housing and wanted to break the cycle of poverty. This experience was a "big... major influence... number one driving force." Her hope was that education would "provide a better life... not have to lean on the government."

Parental or family expectations were also motivating factors for pursuing higher education $(3 ; 43 \%)$ and included wanting to make parents and grandparents happy. For example, one participant thought of pursuing law "mostly to like make my family proud." Another wanted to defy the odds by being the first woman in her family to attend college. Four participants (57\%) reported family as facilitators to attaining their hopes and dreams. These participants had parents and grandparents who encouraged, and in some cases "pushed," education and set high expectations for the future. One participant's grandmother "wanted me to be a star." Another participant lost her father when she was in grade 10 and as the eldest of three, realized the importance of modeling educational attainment for her younger siblings. Three participants (43\%) percent cited self-motivation as a key factor in their achievements such as being a good student. Teachers were only cited by 2 (29\%) participants as dream facilitators. 
Figure 1

Schematic of Findings

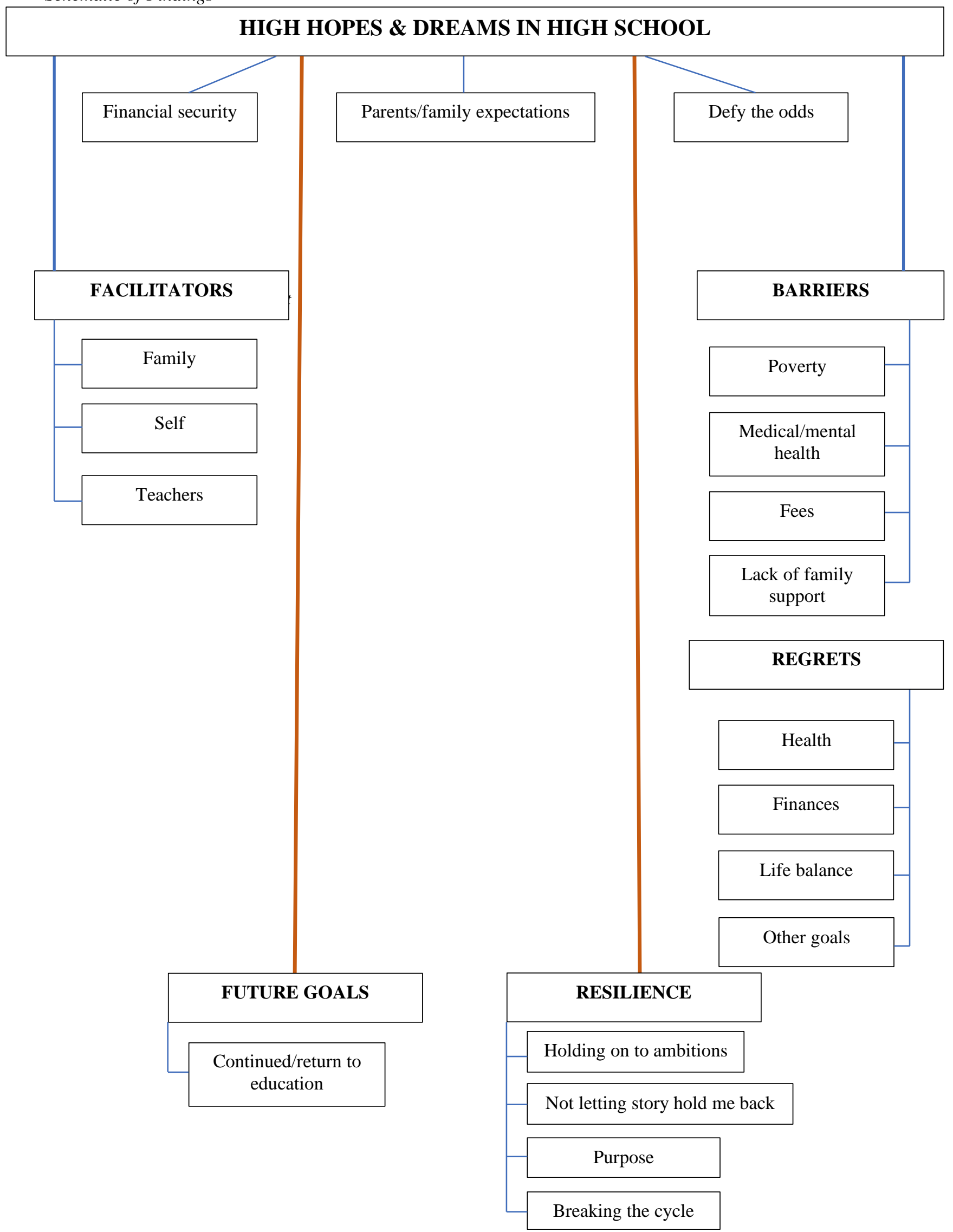




\section{Barriers to Dream Attainment}

Participants reported a number of barriers to dream attainment. Over half $(4 ; 57 \%)$ reported growing up in poverty or low-income, single parent households. The same proportion cited medical and mental health issues such as learning disabilities, psychiatric diagnoses (e.g., anxiety, depression, schizophrenia) and substance use. One participant described how her ADHD created issues with focus and attention, leading to her to become extremely frustrated and run away from education. Another participant summarized the barriers he faced as "a bunch of things was [sic] weighing me down, like... prevent me from actually succeeding. ” In some cases, these barriers led to self-doubt and a sense of lacking control over future hopes and dreams: "A lot of distractions... and a lot of insecurities... so then I started to kind of run away from education... kind of give up... all of which I regret looking back now."

Just under half $(3 ; 43 \%)$ cited lack of family support as a barrier to dream attainment. For one participant, having to find work from the age of 13 and take care of her younger siblings took priority over her education. She says,

"I would definitely have benefited from like more like family support... like accountability support, if that makes sense. Like having someone around me who's like, willing to, you know, force me to take accountability for like my own, you know, choices and mistakes... pointing me to the direction or teaching me... what it means to like, make a vital decision how those decisions not only impact you now, but how it impacts you in the long run. And I didn't really have that type of support when I was younger to kind of explain those things to me... just to have like that, like, skeleton frame framework to kind of be like, you know, this is what you need. These are the things that you can anticipate or you know, expect."

Lack of school support was cited by one participant as a barrier to dream attainment. This participant grew up in a low-income family and describes her experience as,

"going to a school where family income is like super high... and like coming from a low income families like, there wasn't really that much support in the way of like, you know, oh, we, you know, we have students that are in these situations, and also, there wasn't like any healthy dialogue around that. So oftentimes, it's just like, you were about to feel shame and you just wouldn't say anything... you'd missed out on... opportunities to be able to advance in, like, in the school system at that time, at least for me, that's how it was."

Finally, fees and paying for school played a role for $3(43 \%)$ respondents.

\section{Regrets About Incomplete Education}

Nearly half $(3 ; 43 \%)$ expressed regret over not completing their post-secondary education. One participant notes, "because by now I would have had my diploma, I could have had my degree and I could have been working and providing for my family and I could have been doing something I really love doing... I did have aspirations and dreams. ” 
Another participant says,

"Part of me wishes that I would have just stuck with it just to. Have that education, that extra education.... I definitely thought of going back to school multiple times."

Reasons cited include health, finances, life balance, other goals, and a mismatch between interests and chosen program.

Continued education as a future goal and value

Encouragingly, four participants $(57 \%)$ expressed a desire to return to school in the future. Indeed, when asked about their future goals, continued education was the most common response. Participants identified salient values associated with education such as greater "confidence," "a boost in self-identity," and "being a productive member of society, like I'm actually doing something, not just. You know, draining off the welfare system." One participant sees education as "a stepping stone" and plans to return to school to "have more tools under my belt." Others said,

"It's not too late to go back to school."

"They say you're never too old to go back to school... I can finish it."

"The more experience and education you have, the better your chances."

“[Without education] it wouldn't really open... doors... you wouldn't have many career options.”

\section{Resilience}

Overall, participants seem to have adapted well in the face of adversity and four (57\%) reflected back on their educational and occupational pathways positively. One participant noted,

"II'm] trying not to let go of my ambitions... as much as it kills me to have to wait because I want to get out [of government housing], I want to do more to be able to provide... [I'm] trying to get a plan so I can go to school and take care of my kids."

Another participant says,

"I'm no longer in that mindset. And I'm definitely not making it my story anymore... I did grow up in an inner-city community. And I did grow up in like a low, medium-low income... I'm not going to allow [it] to 
hold me back... I'm more aware, and I'm more present. And I'm like, able to just kind of like have a better understanding or have a better grasp on the things that are happening in my life. For me, it's like... breaking my own cycle and not holding onto... that as my story anymore... [I found] an idea of what it is that I need to do and what my purpose is."

\section{Discussions}

The current study investigated the long-term educational and career aspirations and pathways ten years after high school among seven young adults with previous child welfare involvement. Findings make a unique contribution to the literature on education by furthering our understanding of the strengths, resources, and obstacles in achieving educational hopes and dreams among this at-risk population. Overall, a history of CAS involvement did not stop youth from continuing to hope that one day achieving a higher level of education would be possible. Similar to general population peers (McMillen et al., 2003), our sample had high hopes and dreams, but their path to achievement was more arduous and none achieved the dreams they had in high school. Only four out of seven graduated from high school and, although six started a post-secondary program, only one saw it through. This is consistent with previous research demonstrating youth with child welfare involvement are less likely to graduate from high school, less likely to enroll in post-secondary education and, if they do enroll, are less likely to graduate compared to other young adults (Day et al., 2011).

A number of barriers to educational attainment were identified by youth and may account for their disparate educational outcomes. Over half (57\%) reported growing up in poverty or low-income households, in some cases by single parents that required youth to share in the caretaking of younger siblings. Our findings are consistent with research showing that the negative effects on children associated with economic hardship include poorer physical health (Shonkoff et al., 2009), increased risk of serious emotional and behavioural issues (Murdock et al., 2010), lower academic achievement (Sirin, 2005), and mental health issues in adulthood (Wadsworth et al., 2011). Studies have also made clear the cumulative effects of multiple stressors often faced by low-income families (Evans \& English, 2002). Our participants identified a variety of medical and mental health issues as interfering with their educational attainment including psychiatric diagnoses, substance use, and learning disabilities. Although interviews did not probe for experiences of abuse, the sample's previous involvement with CAS means some form of maltreatment did occur that necessitated formal intervention. Maltreated youth often experience complex trauma and this can result in functional deficits across a number of domains (Cook et al., 2005). Such experiences would have presented clear and obvious challenges to participants' educational engagement and achievement. Buckley and colleagues (2016) put it well when they stated that "children who experience ongoing trauma over time... are too busy surviving" (p. 36). Notwithstanding removal from the home, our research reinforces findings from previous work that shows involvement with child welfare services and other disruptive family, neighbourhood, and school experiences can compound traumatic experiences and undermine youth's academic achievement and readiness for post-secondary education (Trout et al., 2008). 
Standing in contrast to the report that caregivers' aspirations for children in care is $40 \%$ less than non-care counterparts (Stoddart, 2012), participants in the current study identified parental expectations as the most common motivator in having educational aspirations. This is consistent with other studies demonstrating the highly influential role of caregivers in promoting educational success in young people (Cheung, Lwin, \& Jenkins, 2012). In particular, research has shown the importance of caregivers, teachers, and other professionals in engaging with youth and demonstrating interest and belief in their dreams, aspirations, and struggles (Clemens et al., 2017). According to Newman (2004), having a warm and redeeming relationship with at least one other person can build resilience and help youth overcome their odds. Believing youth at risk can achieve great things and instilling in them a sense of confidence seems to be an essential ingredient when encouraging success in school and beyond. Yet participants with prior child welfare involvement largely failed to achieve their educational dreams despite having been inspired by the adults in their lives. One possible explanation is that passionate aspirations to chase a dream are just not enough to overcome financial and other structural constraints. Evidence from the current study about lack of finances as an obstacle supports this explanation. Another possible explanation for leaving a post-secondary program before completing it may be due to structural issues or a misfit between individual expectations and the university program (e.g., Naaman, 2021).

Interestingly, only 2 of the 7 participants identified teachers as facilitators to educational attainment. This is surprising given that teachers are among the most frequently cited role models and often make a strong impression on youth (e.g., Bell \& Romano, 2015; Merdinger et al., 2005) including taking a protective role in reducing the negative influence of victimization for youth who feel unsafe at school (Coyle et al., 2021). However, Ferguson and Wolkow (2012) found that teachers tend to have negative perceptions and low expectations for children in care, with some youth feeling labeled as delinquents by teachers. Given that high expectations have been identified as a promotive factor in educational attainment (Flynn \& Tessier, 2011), it may be that some high school teachers had lower expectations of what these youth could accomplish and this may have impacted motivation and subsequent achievement. Teacher training can play an important role in unpacking implicit negative attitudes towards students who are part of the child welfare system or living below the poverty line. For example, a recent study of initial teacher education in the UK found that preservice teachers' understanding of poverty is multidimensional and may be changed (Robson et al., 2021).

Nearly half $(4 ; 43 \%)$ of participants expressed regret over not completing their post-secondary programs. Reasons cited for non-completion included health, finances, life balance, other life goals, and a mismatch between interests and their chosen program. Previous research on post-secondary discontinuance has similarly identified financial and interpersonal problems, lack of peer and parental support, wrong program choice, and personal circumstances as barriers to completion (Jones, 2008; MacKie, 2001; Yorke, 2000; York \& Longdon, 2008). In addition to regret over non-completion, the most common future goal reported by 4 (57\%) was to return to school and complete a previously started degree or initiate a new degree. This points to the value participants continue to place on educational attainment. Young adults spoke about pursuing education not only in terms of providing financial security and opportunities for a better life, but also with associations to core values such as confidence, self-identity, and being 
productive members of society. Internal resources such as self-efficacy and a sense of purpose and control have been cited as important factors in building "identity capital" and renewing a sense of personal agency (Thulien et al., 2019). It seems that for these young adults, the pursuit of education was seen as intrinsically tied to long-term personal fulfillment.

Perhaps the most impressive finding that emerged from this study was the sense of resilience demonstrated by the majority of young adults. This is encouraging given that experiences of maltreatment are consistently associated with poor outcomes and lower resilient capacity (Nishimi et al., 2020). Resilience, defined as the ability to function competently and face future challenges or adversities successfully (Cicchetti \& Rogosch, 2009) is understood as a dynamic process contingent on multiple external and internal factors (Southwick et al., 2014). Participants emphasized education as a vehicle of resilience, a way to break out of the cycle of poverty, leave public housing, and shed the constraints of their past for a better tomorrow. In short, they refused to make adversity their story.

A focus on resilience provides an alternative perspective to the deficit model commonly used in studies of this vulnerable population (Daining \& DePanfilis, 2007) and inspires hope that future targets of intervention will include cultivating resilience and positive adaptation in the face of past maltreatment. At the same time, however, findings indicate that although young adults had both aspirations and resilience, they reported vulnerabilities in other areas such as financial difficulties and mental health challenges and there was an obvious absence of teachers making a positive impact. Our finding of teachers' lack of influence may be due to implicit attitudes and consistent with teachers reproducing social inequalities (Delay, 2020; Pit-Ten \& Glock, 2019). Future research should explore in greater depth what protective factors contribute to resilience among this population and how factors such as type and length of maltreatment impact the ability to develop resilience. Drapeau and colleagues (2007) interviewed adolescents living in out-of-home care and identified several factors that set youth on a path to greater resilience including relationships, self-efficacy, self-reflection, community service, and a sense of achievement. Other resilience scholars have identified contributing factors among at-risk youth such as strong connections to parents and community, effective schools, a sense of competence, goals for the future, social support, and community involvement (Hass \& Graydon, 2009; Masten, 2006). In addition, research has also shown that mentoring relationships can benefit at-risk youth by increasing self-esteem, developing coping skills, and fostering a more positive outlook for the future (Barrera \& Prelow, 2000), significant factors in fostering resilience. Teachers have daily opportunities to mentor students and initial teacher education programs can include the development of relationship building skills with vulnerable students.

\section{Limitations}

The current study has some limitations which must be considered. First, our sample size was small $(\mathrm{N}=7)$ and limited to communities in Ontario, Canada. As such, findings are not representative of all youth with child welfare involvement and cannot be generalized beyond the current sample. Second, although all seven participants reported past involvement with child welfare services, only two reported being removed from their home as children. Our findings therefore apply to individuals with past experiences of CAS involvement, not solely to those who were apprehended, although CAS involvement of any kind characterizes this sample as a high-risk group. We have tried to 
make this distinction clear throughout the manuscript. Finally, it is possible that there may be something unique about the experiences of the youth who chose to be interviewed compared to those who opted out. Despite these limitations, the current study provides more nuanced evidence concerning the facilitators, barriers, and future educational aspirations among young adults with former child welfare involvement.

\section{Conclusion}

This study contributes to the existing literature on youth with child welfare involvement by showcasing young adults' educational and occupational aspirations and pathways ten years after high school. Educational attainment has become an ideology that underpins educational systems worldwide and is widely accepted as a promising life goal associated with a range of social and economic benefits (Baker, 2011). The underlying theory embedded in the current study has been that education makes a difference in everyday life by facilitating access to better jobs, higher earnings, improved standard of living, increased social mobility, and more meaningful social participation (Powdthavee et al., 2015; St. Clair \& Benjamin, 2011), among other important contributions. Conversely, disengagement from education presents risks for young people's physical and mental health, level of social connectedness (Reeve et al., 2016), as well as implications for national economies (FYA, 2016).

Despite the clear value that educational attainment holds, our findings make clear that aspirations are not enough when it comes to educational attainment. Importantly, children and youth in high-risk contexts, such as those with child welfare involvement, are in need of social supports and services that can strengthen the diminished educational chances this vulnerable population faces. Invariably, these children have a history of abuse, neglect, or some other maltreatment and face additional risks that can disrupt key developmental processes and significantly jeopardize youth's academic achievement (Stone, 2007; Trout et al., 2008). Given the level of academic proficiency required for gainful employment in our current society, and the detrimental outcomes associated with low academic achievement, it is more important than ever to understand factors that facilitate and impede educational dream attainment to better inform pathways that can mobilize educational engagement and participation among this population.

The relatively low educational attainment of youth with child welfare involvement is a complex and multifaceted issue. Meltzer and colleagues (2019) note that progressing towards improved educational engagement is an ongoing, continuous, non-linear experience for young people, and that a number of factors may play a role along the way. Our findings echo this sentiment and demonstrate empirically that achieving the educational hopes and dreams from high school is contingent on a number of interconnected factors. As such, solutions will likely require widespread systemic change (Clemens et al., 2017). It must be acknowledged that this requires a tremendous investment of human and material resources including time and money, often compounded by heavy caseloads and administrative requirements among child welfare workers, teachers, and other relevant support systems, undercutting their ability to fully meet the educational needs of children (Stoddart, 2012). 
Education is the great equalizer, but not all education is equal, particularly for children whose families need child welfare services. Research has shown that educational aspirations are critical for obtaining post-secondary education. For individuals with histories of child welfare involvement, aspirations are not enough. Teachers, parents, caregivers, peers and all members of society contribute to building a foundation for individuals to realize their educational dreams. Few influencers share with students the hours, days, years, and conversations to develop aspirations as teachers do. With 5 out of 7 individuals (of our sample) not reporting teachers as facilitators, more research is needed on this topic with this population. Educational researchers provide evidence to inform and inspire initial teacher education and continuing professional development. Researchers and educators are well placed to be world-leading innovators in education, realizing the potential for education to be the great equalizer. Our hope with the current study was to document the educational and occupational pathways taken by young adults with former child welfare involvement and identify the factors that influence positive educational outcomes. Our findings can inform and bring together teachers, parents, caregivers, service providers, and policy makers to better address the broad educational needs of this population and work collectively towards mitigating some of the systemic factors that impede the attainment of youth's educational aspirations.

\section{Acknowledgements}

Acknowledgements: The authors acknowledge the in-kind contributions of their respective institutions. We also thank the research participants for sharing their stories with us.

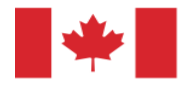
Social Sciences and Humanities Research Council of Canada Canadăa

\section{Conseil de recherches en sciences humaines du Canada}

\section{References}

Baker, D. P. (2011). The future of the schooled society: The transforming culture of education in post-industrial society. In Hallinan, M. T. (Ed.), Frontiers in sociology of education. Springer: Netherlands.

Barrera, M., \& Prelow, H. (2000). Interventions to promote social support in children and adolescents. In D. Cicchetti, J. Rappaport, I. Sandler, \& R. Weissberg (Eds.), The promotion of wellness in children and adolescents. Washington, DC: Child Welfare League of America, Inc.

Bell, T., \& Romano, E. (2015). Child resilience in out-of-home care: Child welfare worker perspectives. Children and Youth Services Review, 48, 49-59.

Biehal, N. (2005). Working with adolescents at risk of out of home care: The effectiveness of specialist teams. Children and Youth Services Review, 27, 1045-1059.

Biehal, N., Clayden, J., \& Byford, S. (2000). Home or away? Supporting young people and families. London National Children's Bureau. 
Buckley, A. M., Lotty, M., \& Meldon, S. (2016). What happened to me? Responding to the impact of trauma on children in care: Trauma informed practice in foster care. The Irish Social Worker, 35-40.

Burns, B., Phillips, S. D., Wagner, H. R., Barth, R. P., Kolko, D. J., Campbell, Y., et al. (2004). Mental health need and access to mental health services by youths involved with child welfare: A national survey. Journal of the American Academy of Child and Adolescent Psychiatry, 43, 960-970.

Canadian Child Welfare Research Portal. (2021). Out-of-home care. Retrieved from https://cwrp.ca/out-home-care

Cheung, C., Lwin, K., \& Jenkins, J. M. (2012). Helping youth in care succeed: Influence of caregiver involvement on academic achievement. Children and Youth Services Review, 34(6), 1092-1100.

Child and Family Services Act. (1990). Section 1(1), Government of Ontario. Retrieved from

http://www.e-laws.gov.on.ca/html/statutes/english/elaws_statutes_90c11_e.htm

Cicchetti, D., \& Rogosch, F. A. (2009). Adaptive coping under conditions of extreme stress: Multilevel influences on the determinants of resilience in maltreated children. New Directions for Child and Adolescent Development, 124, 47-59.

Clemens, E. V., Helm, H. M., Myers, K., Thomas, C., \& Tis, M. (2017). The voices of youth formerly in foster care: Perspectives on educational attainment gaps. Children and Youth Services Review, 79, 65-77.

Connor, D. F., Doerfler, L. A., Toscano, P. F., Volungis, A. M., \& Steingard, R. J. (2004). Characteristics of children and adolescents admitted to a residential treatment center. Journal of Child and Family Studies, 13, 497-510.

Cook, A., Spinazzola, J., Ford, J., Lanktree, C., Blaustein, M., Cloitre, M., et al. (2005). Complex trauma in children and adolescents. Psychiatric Annals, 35, 390-398.

Courtney, M. E., Piliavin, I., Grogan-Kaylor, A., \& Nesmith, A. (2001). Foster youth transitions to adulthood: A longitudinal view of youth leaving care. Child Welfare, 80(6), 685-717.

Courtney, M E., Roderick, M., Smithgall, C., Gladden, R. M., \& Nagaok, J. (2004). The educational status of foster children. Chicago, IL: Chapin Hall Center for Children.

Courtney, M. E., \& Terao, S. (2006). Emotional and behavioral problems of foster youth: Early findings of a longitudinal study. In F. A. Villarruel \& T. Luster (Eds.), The crisis in youth mental health: Critical issues and effective programs (pp. 105-109). Westport, CT: Praeger Publishers.

Coyle, S., Weinreb, K. S., Davila, G., \& Cuellar, M. (2021). Relationships matter: The protective role of teacher and peer support in understanding school climate for victimized youth. Child \& Youth Care Forum, 1-23.

Daining, C., \& DePanfilis, D. (2007). Resilience of youth in transition from out-of-home care to adulthood. Children and Youth Services Review, 29, 1158-1178.

Day, Dworsky, Fogarty, \& Damashek, (2011). An examination of post-secondary retention and graduation among foster care youth enrolled in a four-year university. Children and Youth Services Review, 33, 2335-2341. 
Delay, C. (2020). Youngsters' choices within the field of vocational education in French-speaking Switzerland: The interplay of institutional influences, peer-group and habitus. Journal of Youth Studies, 25(1), 116-135. https://doi.org/10.1080/13676261.2020.1849583

Dill, K. (2012). Improving the educational achievements of young people in out-of-home care. Child and Youth Services Review, 34, 1081-1083.

Doyle, J. (2007). Child protection and adult crime: Using investigator assignment to estimate causal effects of foster care. Journal of Political Economy, 116(4), 746-772.

Drapeau, S., Saint-Jacques, M.-C., Lepine, R., Begin, G., \& Bernard, M. (2007). Processes that contribute to resilience among youth in foster care. Journal of Adolescence, 30, 977-999.

Dworkin, S. L. (2012). Sample size policy for qualitative studies using in-depth interviews. Archives of Sexual Behavior, 41, 1319-1320.

Esposito, T., Trocmé, N., Chabot, M., Shlonsky, A., Collin-Vézina, D., \& Sinha, V. (2013). Placement of children in out-of-home care in Québec, Canada: When and for whom initial out-of-home placement is more likely to occur. Children and Youth Services Review, 35, 2031-2039.

Evans, G. W., \& English, K. (2002). The environment of poverty: Multiple stressor exposure, psychophysiological stress, and socioemotional adjustment. Child Development, 73, 1238-1248.

Ferguson, H. B. \& Wolkow, K. (2012). Educating children and youth in care: A review of barriers to school progress and strategies for change. Children and Youth Services Review, 34, 1143-1149.

Finnie, R. (2012). Access to post-secondary education: The importance of culture. Education Policy Research Initiative Working Paper No. 2012 - 02. University of Ottawa.

Fisher, D., Rubenson, K., Jones, G., \& Shanahan, T. (2009). The political economy of post- secondary education: A comparison of British Columbia, Ontario, and Quebec. Higher Education: The International Journal of Higher Education and Educational Planning, 57, 549-566.

Flynn, R. J., \& Tessier, N. G. (2011). Promotive and risk factors as concurrent predictors of educational outcomes in supported transitional living: Extended care and maintenance in Ontario, Canada. Children and Youth Services Review, 33, 2489-2503.

Frensch, K., \& Cameron, G. (2002). Treatment of choice or a last resort? A review of residential mental health placements for children and youth. Child and Youth Care Forum, 31, 307-339.

FYA. 2016. Renewing Australia's Promise: Report Card 2016. Melbourne: Foundation for Young Australians. Online.

Glock, S., \& Kleen, H. (2020). Preservice teachers' attitudes, attributions, and stereotypes: Exploring the disadvantages of students from families with low socioeconomic status. Studies in Educational Evaluation, 67, 100929. https://doi.org/10.1016/j.stueduc.2020.100929 
Harder, A. T., Eenshuistra, A., \& Knorth, E. J. (2021). Feeling better: Experiences and needs of adolescents and professionals regarding their mentorship relationship residential youth care. Child \& Youth Care Forum, 1-19.

Hass, M., \& Graydon, K. (2009). Sources of resiliency among successful foster youth. Children and Youth Services Review, 31, 457-463.

Heerde, J. A., Hemphill, S. A., \& Scholes-Balog, K. E. (2018). The impact of transitional programmes on posttransition outcomes for youth leaving out-of-home care: A meta-analysis. Health and Social Care in the Community, 26(1), 15-30.

Hildyard, K. L., \& Wolfe, D. A. (2002). Child neglect: Developmental issues and outcomes. Child Abuse \& Neglect, 26(607), 679-695.

Holden, M. J., Izzo, C., Nunno, M., Smith, E. G., Endres, T., Holden, J. C., \& Kuhn, F. (2010). Children and residential experiences: A comprehensive strategy for implementing a research-informed program model for residential care. Child Welfare, 89(2), 131-149.

Jackson, S., \& McParlin, P. (2006). The education of children in care. The Psychologist, 19(2), 90-93.

James, S., Leslie, L. K., Hurlburt, M. S., Slymen, D. J., Landsverk, J., \& Davis, I. (2006). Children in out-of-home care: Entry into intensive or restrictive mental health and residential care placements. Journal of Emotional and Behavioural Disorders, 14, 196-208.

Jones, L. (2008). Adaptation to early adulthood by a sample of youth discharge from a residential education placement. Child \& Youth Care Forum, 37(5-6), 241-263.

Klodnick, V. V., \& Samuels, G. (2020). Building home on a fault line: Aging out of child welfare with a serious mental health diagnosis. Child \& Family Social Work, 25(3), 704-713.

Kolko, D. J., Hurlburt, M. S., Zhang, J., Barth, R. P., Leslie, L. K., \& Burn, B. J. (2010). Posttraumatic stress symptoms in children and adolescents referred for child welfare investigation. Child Maltreatment, 15(1), 48-63.

Lazareva, \& Zakharov, A. (2020). Teacher wages and educational outcomes: evidence from the Russian school system. Education Economics, 28(4), 418-436.

Leonard, S. S., \& Gudiño, O. G. (2021). Beyond school engagement: School adaptation and its role in bolstering resilience among youth who have been involved with child welfare services. Child \& Youth Care Forum, 50(2), 277-306.

Lindsey, D., \& Shlonsky, A. (2008). Child welfare research. Advances for practice and policy. London, UK: Oxford University Press.

MacKie, S. (2001). Jumping the hurdles: Undergraduate student withdrawal behaviour. Innovations in Education and Teaching International, 38(3), 265-276. 
Masten, A. S. (2006). Promoting resilience in development: A general framework for systems of care. In R. J. Flynn, P. M. Dudding, \& J. G. Barber (Eds.), Promoting resilience in child welfare (pp. 3-17). Ottawa, ON: University of Ottawa Press.

McMillen, C., Auslander, W., Elze, D., White, T., \& Thompson, R. (2003). Educational experiences and aspirations of older youth in foster care. Child Welfare, 82, 475-495.

Meltzer, A., Powell, A., \& Saunders, I. (2019). Pathways to educational engagement: An exploratory study of outcomes from an Australian school-based youth mentoring program. Journal of Youth Studies, 23(5), 545-560.

Merdinger, J. M., Hines, A. M., Osterling, K. L., \& Wyatt, P. (2005). Pathways to college for former foster youth: Understanding factors that contribute to educational success. Child Welfare, 84(6), 867-896.

Murdock, S., Zey, M., Cline, M. E., \& Klineberg, S. (2010). Poverty, educational attainment, and health among America's children: Current and future effects of population diversification and associated socioeconomic change. Journal of Applied Research on Children: Informing Policy for Children at Risk, 1, 1-33.

Naaman, H. (2021). The academic dropout wheel analyzing the antecedents of higher education dropout in education studies. The European Educational Researcher, 4(2), 133-153.

Newman, T. (2004). What works in building resilience? Barkingside, England: Barnardos.

Nishmi, K., Choi, K. W., Davis, K. A., Powers, A., Bradley, B., \& Dunn, E. C. (2020). Features of childhood maltreatment and resilient capacity in adulthood: Results from a large, community-based sample. Journal of Traumatic Stress, 33(5), 665-676.

OECD (2015), Education at a Glance 2015: OECD Indicators, OECD Publishing, Paris. DOI: http://dx.doi.org/10.1787/eag-2015-en

OECD (2021). How much are teachers and school heads paid? In Education at a Glance 2021: OECD Indicators, OECD Publishing, Paris. DOI: https://doi.org/10.1787/bc0586e8-en

Ontario Association of Children's Aid Societies (2008). Gateway to success: OACAS survey of the educational status of crown wards and former crown wards, age 16 to 21. Toronto, Ontario: Ontario Association of Children's Aid Societies.

Ontario Association of Children's Aid Societies. (2021). Children's aid \& child protection. Retrieved from http://www.oacas.org/childrens-aid-child-protection/

O’Sullivan, T. (2011). Decision Making in Social Work (Second Edition). Basingstoke: Palgrave MacMillan.

Pit-ten Cate, I. M., \& Glock, S. (2019). Teachers' implicit attitudes toward students from different social groups: A meta-analysis. Frontiers in Psychology, 10.

Powdthavee, N., Lekfuangufu, W. N., \& Wooden, M. (2015). What's the good of education on our overall quality of life? A simultaneous equation model of education and life satisfaction for Australia. Journal of Behavioral and Experimental Economics, 54, 10-21. 
Relmasira, S. C., Lai, Y. C., \& So, C. F. H. (2021). Future jobs: Indonesian Primary Students' Aspirations and Teachers' predictions. The European Educational Researcher, 4(2), 209-225.

Reeve, R., Marjolin, A., Muir, K., Powell, A., Hannigan, N., Ramia, I., \& Etuk, L. (2016). Australia’s Social Pulse. Centre for Social Impact: UNSW Australia, Sydney and UWA, Perth.

Reid, C., \& Dudding, P. (2006). Building a future together: Issues and outcomes for transition-aged youth. Ottawa, ON: Centre of Excellence for Child Welfare.

Robson, D., Mtika, P., Graham, A., \& MacDougall, L. (2021). Student teachers' understandings of poverty: insights for initial teacher education. Journal of Education for Teaching, 47(1), 104-117.

Rosenfeld, L. B., \& Richman, J. M. (2003). Social support and educational outcomes for students in out-of-home care. Children \& Schools, 25(2), 69-86.

Ryan, J. P., Davis, R. K., \& Yang, H. (2001). Reintegration services and the likelihood of adult imprisonment: A longitudinal study of adjudicated delinquents. Research on Social Work Practice, 11(3), 321-337.

Saint-Girons, M., Trocmé, N., Esposito, T., \& Fallon, B. (2020). Children in Out-of-Home Care in Canada in 2019. CWRP Information Sheet \#211E. Montreal, QC: Canadian Child Welfare Research Portal.

Shonkoff, J. P., Boyce, W. T., \& McEwen, B. S. (2009). Neuroscience, molecular biology, and the childhood roots of health disparities: Building a new framework for health promotion and disease prevention. Journal of the American Medical Association, 301, 2252-2259.

Sirin, S. R. (2005). Socioeconomic status and academic achievement: A meta-analytic review of research. Review of Educational Research, 75(3), 417-453.

Southwick, S. M., Bonanno, G. A., Masten, A. S., Panter-Brick, C., \& Yehuda, R. (2014). Resilience definitions, theory, and challenge: Interdisciplinary perspectives. European Journal of Psychotraumatology, 5(1), 2533825352

St. Clair, R., \& Benjamin, A. (2011). Performing desires: The dilemma of aspirations and educational attainment. British Educational Research Journal, 37(3), 501-517.

Stein, M. (2008). Resilience and young people leaving home. Child Care in Practice, 14(1), 35-44.

Stein, M. (2019). Supporting young people from care to adulthood: International practice. Child \& Family Social Work, 24, 400-405.

Stoddart, J. K. (2012). Using research and outcome data to improve educational services and supports for young people in care: A case study of a local children's aid society in Ontario. Children and Youth Services Review, 34, 11541160.

Stone, S. (2007). Child maltreatment, out-of-home placement and academic vulnerability: A fifteen-year review of evidence and future directions. Child and Youth Services Review, 29, 139-161. 
Thulien, N. S., Gastaldo, D., McCay, E., \& Hwang, S. W. (2019). "I want to be able to show everyone that it is possible to go from being nothing in the world to being something": Identity as a determinant of social integration. Children and Youth Services Review, 96, 118-126.

Trout, A., Hagaman, J., Casey, K., Reid, R., \& Epstein, M. (2008). The academic status of children and youth in outof-home care: A review of the literature. Children and Youth Services Review, 30, 979-994.

Watt, T., Faulkner, M., Bustillos, S., \& Madden, E. (2019). Foster care alumni and higher education: A descriptive study of post-secondary achievements of foster youth in Texas. Child and Adolescent Social Work Journal, 36, 399-408.

Wadsworth, M. E., Raviv, T., Santiago, C. D., \& Etter, E. M. (2011). Testing the adaptation to poverty-related stress model: Predicting psychopathology symptoms in families facing economic hardship. Journal of Clinical Child and Adolescent Psychology, 40, 646-657.

Yorke, M. (2000). Smoothing the transition into higher education: What can be learned from student non-completion. Journal of Institutional Research, 9(1), 78-88.

Yorke, M., \& Longden, B. (2008). The first-year experience of higher education in the UK: final report. York, UK: The Higher Education Academy.

\section{Corresponding Author Contact Information: \\ Author name: Christina Dimakosa \\ University, Country: University of Toronto, Canada \\ Email: christina.dimakos@mail.utoronto.ca}

Please Cite: Dimakos, C., Loomis, C., O’Malley, B., Lamont, S., Singh, G., Pelletier, J., Christens, B., Wright, C., Peters, R. (2022). Aspirations Are Not Enough: Barriers to Educational Attainment for Youth Involved with Child Welfare. The European Educational Researcher, 5(1), 105- 127. DOI: https://doi.org/10.31757/euer.516

Copyright: (C) 2022 EUER. This is an open-access article distributed under the terms of the Creative Commons Attribution License, which permits unrestricted use, distribution, and reproduction in any medium, provided the original author and source are credited. 